\title{
Tensile Strength of Ropes and Friction Hitch Used in Tree Climbing Work
}

\author{
Leonardo Bianchini *(D), Rodolfo Picchio (D), Andrea Colantoni ${ }^{(D)}$, Marco Scotolati, Valerio Di Stefano \\ and Massimo Cecchini (D)
}

check for

updates

Citation: Bianchini, L.; Picchio, R.; Colantoni, A.; Scotolati, M.;

Di Stefano, V.; Cecchini, M. Tensile

Strength of Ropes and Friction Hitch

Used in Tree Climbing Work. Forests

2021, 12, 1457. https://

doi.org/10.3390/f12111457

Received: 22 September 2021

Accepted: 24 October 2021

Published: 26 October 2021

Publisher's Note: MDPI stays neutral with regard to jurisdictional claims in published maps and institutional affiliations.

Copyright: (C) 2021 by the authors Licensee MDPI, Basel, Switzerland. This article is an open access article distributed under the terms and conditions of the Creative Commons Attribution (CC BY) license (https:// creativecommons.org/licenses/by/ $4.0 /)$.
Department of Agriculture and Forest Sciences (DAFNE), University of Tuscia, Via S. Camillo de Lellis snc, 01100 Viterbo, Italy; r.picchio@unitus.it (R.P.); colantoni@unitus.it (A.C.); scotomarco92@gmail.com (M.S.); v.distefano@unitus.it (V.D.S.); cecchini@unitus.it (M.C.)

* Correspondence: 1.bianchini@unitus.it; Tel.: +39-0761-357-357

\begin{abstract}
Tree climbing techniques for arboriculture are becoming more and more popular, but like any work activity, there are risks for the operator. The PPE (personal protective equipment) and protective systems studied here include semi-static ropes and friction hitches. The work rope/friction hitch system is a combination that many operators rely on, but unlike current mechanical rope clamps and descenders, they do not have European certifications. For this reason, tensile tests were carried out using a traction bench on rope/knot systems. Two rope models and two types of knots were used to stress the systems and materials as much as possible, so as to observe the resulting ratios. A total of 36 tests were carried out in which measurements were taken, including applied load in traction, knot creep, and rope diameter changes. Several results were obtained, including a maximum load of $18.7 \mathrm{kN}$, a maximum slip of $9.6 \mathrm{~cm}$ and a maximum diameter variation of $3 \mathrm{~mm}$. This work represents a preliminary investigation for verifying the relationship between work ropes and friction knots. Relationships among the variables were observed; differences emerged mainly as a function of the type of knot used rather than the type of rope used. The data obtained is also important for applications towards improving preventative safety measures.
\end{abstract}

Keywords: urban forestry; static load; ropework; knots; safety

\section{Introduction}

Arboriculture, better known as "urban forestry", is an area that is making great strides in scientific research and technical solutions [1-3]. A growing focus on the proper planning and management of trees in the city or urban-forest interfaces has led to an increased need for technicians and operators employed in this sector [4].

Operators are exposed to a multitude of risks, given that they work at considerable heights. In fact, as noted by several authors, this typology of arboriculture is a dangerous activity, with a high number of injuries every year occurring in many countries [5-8]. Pruning and controlled felling (rigging) are the most common and frequent practices, which in these contexts require work "in canopy". Among the various techniques for reaching the tree canopy, rope-based methods are the most commonly applied in tree climbing.

In addition to management and maintenance, there has been further interest in tree climbing for the purposes of ecology. It has not previously been considered necessary to examine the canopy up close; however, researchers have found that there is much to learn by observations which requires this type of technique [9]. Equipment (or personal protective equipment; PPE) includes the ropes used for ascent and movement in order to examine the plant, and the friction systems that ensure the safety of the operator.

Work ropes can be of various types; in particular for tree work, they are kernmantle, i.e., ropes with a core and an outer covering - a core that provides tensile strength and an outer coating to protect them from abrasion. They can be made of different materials and have different diameters. In particular, the latter depends on the ascent technique used by 
the operator: the SRT (single rope technique) with $11 \mathrm{~mm}$ ropes, for example the semi-static AXIS $11 \mathrm{~mm}$ rope, is intended for work at heights- the standard diameter ensures good grip to facilitate maneuvers; the DRT (doubled rope technique) with $13 \mathrm{~mm}$ ropes, e.g., the XTC 16, is designed specifically for the demanding needs of the professional arborist, with high abrasion resistance.

In recent years, more and more mechanical friction systems have been developed, which are produced in accordance with national and international standards. Despite the certifications of the ascender, it is necessary to use them with the safety precautions that the manufacturer provides; plus, not all ascenders are suitable for any type of rope [10]. Systems that employ friction hitch are still widely used by $60 \%$ of operators [11]; however, this is not an ascender, descender, or positioning system that is built according to technical standards [12] (Personal protective equipment for fall protection-Rope access systemsEC [13] (descent devices)), or [13] (Personal protective equipment for positioning at work and prevention of falls from above). This aspect of friction knots does not fall within legal requirements - there are clearly some technical difficulties. Given the fact that very little scientific literature is available on this subject, there is a need to gain more knowledge about the defects and advantages of the use of friction hitches.

For arborists and tree climbers, making knots is necessary for tying branches, anchoring work systems or equipment, and for providing safety. Friction hitches are used for access, ascent, and positioning. The knots which are most frequently used for this purpose are the Tautline, Prusik, Valdotain hitch, Blake's hitch, Machard, Schwabisch, Distel, and Knut; these change according to the techniques and equipment used [14]. Some knots have been tested through use in other fields such as speleology and rock climbing [15]. For arboriculture, Kane (2012) studied the use of ropes and knots in rigging, which is one of their most dangerous uses, given the large loads and oscillations of wood logs. Some authors stated that the breaking point cannot be calculated, given the large number of implied variables [16], but these difficulties are common in most of the sciences applied to forestry work and can be overcome by increasing the observation numbers and applying a rigorous statistical approach.

Kane (2012) noted that the breaking load and specific strength were more closely linked to the differences between the ropes than those between the hitches [15]. In addition, Kane (2012) has shown the incompatibility of tooth blockers with falls, and he showed that in Tachyon and Velocity ropes, the blocker completely damaged the sheath with a stopping distance of more than $2 \mathrm{~m}$, but without damaging the core [10]. Tree climbers should be aware that the use of some (and presumably most) tree climbing ropes are not suitable for ascension and, presumably, for use with most toothed ascenders [10].

One of the most commonly used knots is the Valdotain tresse hitch (one-way knot) [17], and one of the most studied knots is the prusik (two-way knot) [18,19]. The prusik is a two-way friction hitch (it can be used in both directions of the string) that can be used to create movable anchor points on both double ropes and single ropes. The Valdotain tresse is a friction hitch widely used in double rope work because it is very soft and sensitive; it must be made using a lanyard smaller than the rope. Tests and publications on Prusik were carried out by other authors, which have provided useful information [20]. Evans states that information and popular knowledge exist regarding the prusik hitch; however, this information is not available to everyone. He also claims that such information is crucial, as climbers risk their lives using this knot [20].

As mentioned above, there is a lack in the current technical and scientific literature on friction hitches, and the current specific legislation in different countries is unclear. One common situation is that friction knots made by an arborist are not recognized as PPE and, consequently, cannot be used for climbing and tree canopy handling. However, all agree that understanding how friction knots work is crucial for making decisions on which human lives depend and that, with increased knowledge, it might be possible to start training workers to become certified in knots $[20,21]$. 
This study is aimed at observing and defining the dynamics of interaction between ropes and friction knots under high stress. The purpose of the tensile tests carried out in this work was to test the working rope and friction hitch system, to verify variations in rope characteristics and, consequently, to ascertain possible risks for the operator; it was also to verify the behavior of the friction knots, so as to provide more information to help arboriculturists in their choice of knot and rope. As stated by other authors, it is necessary to know the loads that are applied in tree climbing $[22,23]$. The goal of this work was not to define the best knot to use, but to pave the way for a series of studies in order to understand the behavior of friction knots and to define which types of rope are best for combination with such knots-both in terms of size, and in the future, also in terms of material. This is to increase knowledge that may also be useful in the drafting of uniform international standards, since the results of research conducted by Lim et al. revealed discrepancies and raised doubts about the inclusion of common safety categories in standards [7].

\section{Materials and Methods}

This study required tensile tests on ropes and knots used while working at a height on trees using ropes. It was conducted at the Wood Science and Technology Laboratory in the DAFNE department of the University of Tuscia.

The experimental scheme consists of 36 overall tests carried out with 2 types of rope, on which 2 types of friction hitches were applied with special lanyards. Two friction hitches were chosen: the Prusik and the Valdotain hitch $[8,17,24]$. For each type of rope/knot, 3 pieces of rope and 3 cords were used. On each of these sections and cords, 3 traction tests were carried out. Here, the focus is on the properties of individual knots undergoing a slow pull on a semi-static rope. The characteristics of the ropes used and the lanyard for the friction hitch are shown in Table 1.

Table 1. Characteristics of ropes and lanyards used.

\begin{tabular}{ccccc}
\hline Rope & Manufacturer & Material & Diameter mm & Breaking Load Declared kN \\
\hline Axis & Petzl & Polyester, polyamid & 11 & 22 \\
XTC 16 & Yale Cordage & Polyamid & 13 & 24 \\
Timber prusik cord & Tendon & Polyester, technora & 8 & 22 \\
\hline
\end{tabular}

A total of 4 different treatments were performed for the test, with 9 replicas per treatment:

- Axis rope system and Prusik (AP);

- Axis rope system and Valdotain tresse (AT);

- $\quad$ XTC rope system and Prusik (XP);

- $\quad$ XTC rope system and Valdotain tresse (XT).

The traction tests were performed with a Metrocom traction bench from Comazzi, with $100 \mathrm{kN}$ of maximum traction. The upper part of the system was anchored with an 8 knot [25] directly to a large rigging plate fixed on the traction bench, while to the lower part, a carabiner was added-to which the friction hitch lanyard was anchored. Table 2 shows the characteristics of the carabiner and rigging plate.

Table 2. Characteristics of the carabiner and rigging plate.

\begin{tabular}{ccccc}
\hline & Manufacturer & Material & Breaking Load kN & Mass g \\
\hline X-large c steel screw sleeve & Kong & Carbon steel & 50 & 240 \\
Bat plate s & DMM & Heat-treated aluminium & 60 & 159 \\
\hline
\end{tabular}

Ropes were donated by two companies in the sector; friction hitches were selected based on their frequency of use by climbers and studies in the literature (Evans, 2012; Proto et al., 2016). 
The methodology used for this work, which follows UNI EN 1891 standard-test methods for equipment against falls from a height, involves the use of a traction bench for tensile tests [25]. However, changes have been made from the norm in order to run the tests. These changes in the testing standard [25] are assumed not to have led to substantial differences in testing. The rope was cut into $90 \mathrm{~cm}$ lengths, and one end was tied with an 8 -knot. These 8-knots were tied as short as possible, yielding a rope length of $\sim 30 \mathrm{~cm}$ for each sample. The $8 \mathrm{~mm}$ friction hitch lanyards were all the same size, and slings on both ends were certified in accordance with the EN566:2006 standard [26]. Figure 1 shows the diagram of the rope/friction hitch system anchored to the traction bench (Figure 1) [25].

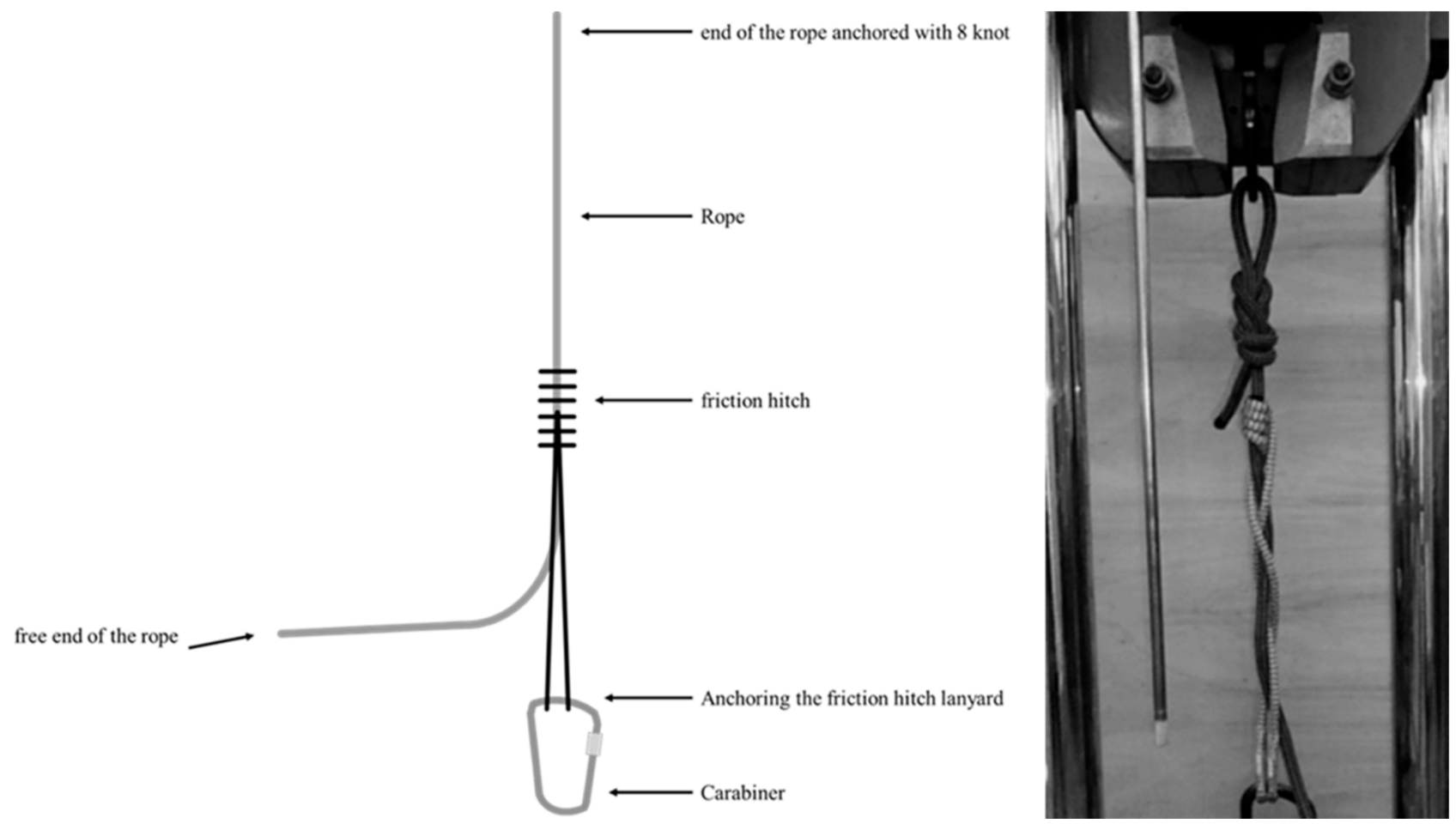

Figure 1. Diagram of the rope/friction hitch system anchored to the traction bench. The lower anchorage consists of a carabiner on which the two ends of the friction knot lanyard are inserted. The upper anchorage consists of an 8 knot.

The traction bench has a stroke of $250 \mathrm{~mm}$ in length, identifiable by a graduated rod; it was decided to take measurements at 6 different points-one before the start of the test, and the others at every $50 \mathrm{~mm}$ along the traction:

- L0-initial state;

- L1-50 mm progress;

- $\quad$ L2-100 mm progress;

- L3-150 mm progress;

- L4-200 mm progress;

- L5-250 mm progress.

At every $50 \mathrm{~mm}$ of traction progression the machine was stopped, and measurements were taken to assess:

- $\quad$ the load to which the rope/node system has been subjected $(\mathrm{C}, \mathrm{kN})$;

- sliding of the clutch knot along the rope $(\mathrm{S}, \mathrm{cm})$;

- variation of the diameter of the rope $(\Delta \mathrm{f}, \mathrm{mm})$.

The temperature of the system near the friction hitch via thermal imaging camera was detected at the beginning and end of each test. The model used was a FLIR C2, a small device designed for mechanical/electrical applications with high precision, as the C2 sensor manages to capture imperceptible temperature differences that also allow the 
understanding and detection of heat losses and any construction deficiencies present. Its temperature measurements range from $-10^{\circ} \mathrm{C}$ to $150{ }^{\circ} \mathrm{C}$; it was used to check for any temperature differences between the start and end of the tests generated by friction of the knot lanyard on the traction rope (Figure 2). In dynamic falling situations, the friction that develops raises the temperature, and the strands tend to melt-leading to permanent damage to the rope. This test was necessary because of the weakness at high temperatures of the materials used in these ropes; as such, we wanted to see if this type of test could lead to this type of damage.

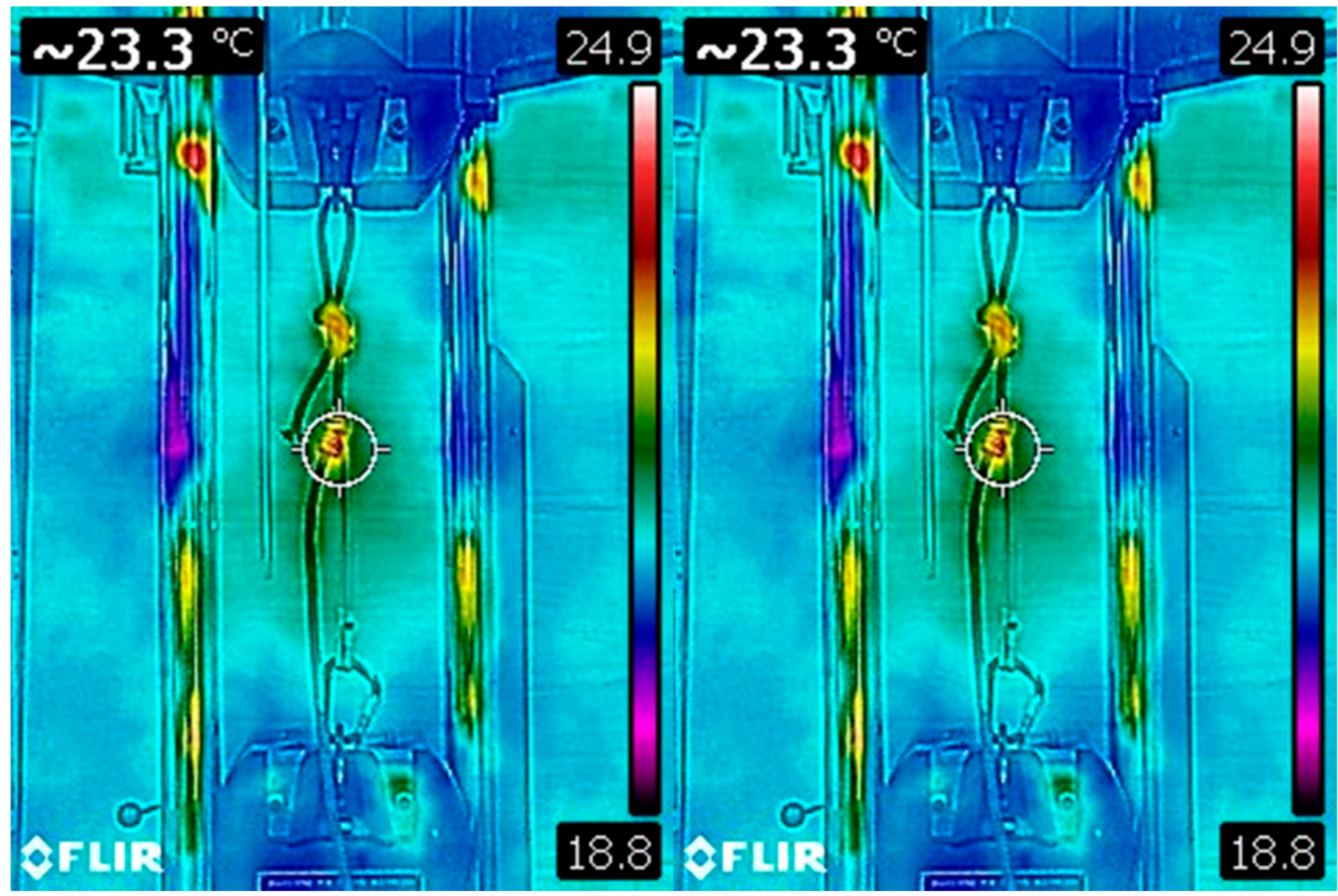

Figure 2. Photos of the camera before and after testing.

Before proceeding with each test, the system was put into tension with a load of $3 \mathrm{kN}$ in order to tighten the 8-knot, which had the sole function of anchoring the rope to the machine. Once this operation had been carried out, the machine was returned to its original position and the friction knot was correctly repositioned.

Additionally, ambient temperature and humidity data were taken before each test using Babuc humidity and temperature sensors. The psychrometric probe was equipped with a duct where the two sensors were housed, which protected it from solar radiation; in this duct, the air was forced through by a fan at a speed of approximately $4 \mathrm{~m} / \mathrm{s}$.

\section{Statistical Analysis}

Statistical analyses were carried out with StatisticaTM version 7.1 (TIBCO Software Inc., Palo Alto, CA, USA). Data distribution was plotted and checked for normality and homogeneity of variance using the Lilliefors and Levene tests, respectively. The data on ambient temperature and humidity and the temperature of ropes were analyzed using a one-factor analysis of variance (ANOVA). Data of the pulling test were analyzed using a factorial MANOVA to test for significant multivariate effects between the rope (A and $X)$ and the friction hitch ( $\mathrm{P}$ and $\mathrm{T})$, using the following variables: load applied to the system, slippage of the friction knot on the rope and change in rope diameter. The Tukey HSD test was used 
to pinpoint differences in specific treatments; this post hoc multiple comparison of the means test was applied at a 95\% family-wise confidence level $(p=0.05)$. Multiple regression was applied to test for how much the dependent variable $(C)$ was affected by changes in independent variables $(S, \Delta \mathrm{f})$.

\section{Results and Discussion}

It is often necessary to construct a rope system with one or more knots. Therefore, it is important to understand the characteristics of the knots in terms of strength and behavior in order to comprehend the tolerance levels of the system-this leads to various and sometimes conflicting notions and information among climbers, which cannot be backed up by reliable sources. It is true that there is a good deal of hearsay rather than real facts $[20,24]$.

The air temperatures detected with the psychrometer during the tests ranged from a maximum of $22.1^{\circ} \mathrm{C}$ to a minimum of $18.5^{\circ} \mathrm{C}$, with a difference of $3.7^{\circ} \mathrm{C}$, while humidity averaged at around $60 \%$. It is hypothesized that this difference did not significantly affect the reaction of the materials; the data tested with one way ANOVA did not give any significant differences for $p=0.05$. A difference in temperature of the rope at the beginning and at the end of the test, measured with the thermal imaging camera, was detected in the four treatments, which showed some small variations in temperature (AP $6.2{ }^{\circ} \mathrm{C}, \mathrm{AT} 6.8^{\circ} \mathrm{C}$, $\mathrm{XP} 6.7^{\circ} \mathrm{C}, \mathrm{XT} 3.1^{\circ} \mathrm{C}$ ). As expected, there were no significant differences. The data was tested with one way ANOVA $(p=0.05)$.

The results for the load applied to the rope/clutch system indicated some differences (Figure 3). Up to the first measurement point (L1), no differences emerged between the four treatments (AP, AT, XP, XT). As the test progressed, the first difference emerged between the treatments, between the Valdotain braid and the Prusik knot. Moving on to point L2, the load trend for the AP and XP treatments increased by $16.7 \%$ compared to treatments with the Valdotain tresse. The trend for AT and XT remained almost identical until point L5, where there was a slight, insignificant difference of $7.5 \%$.

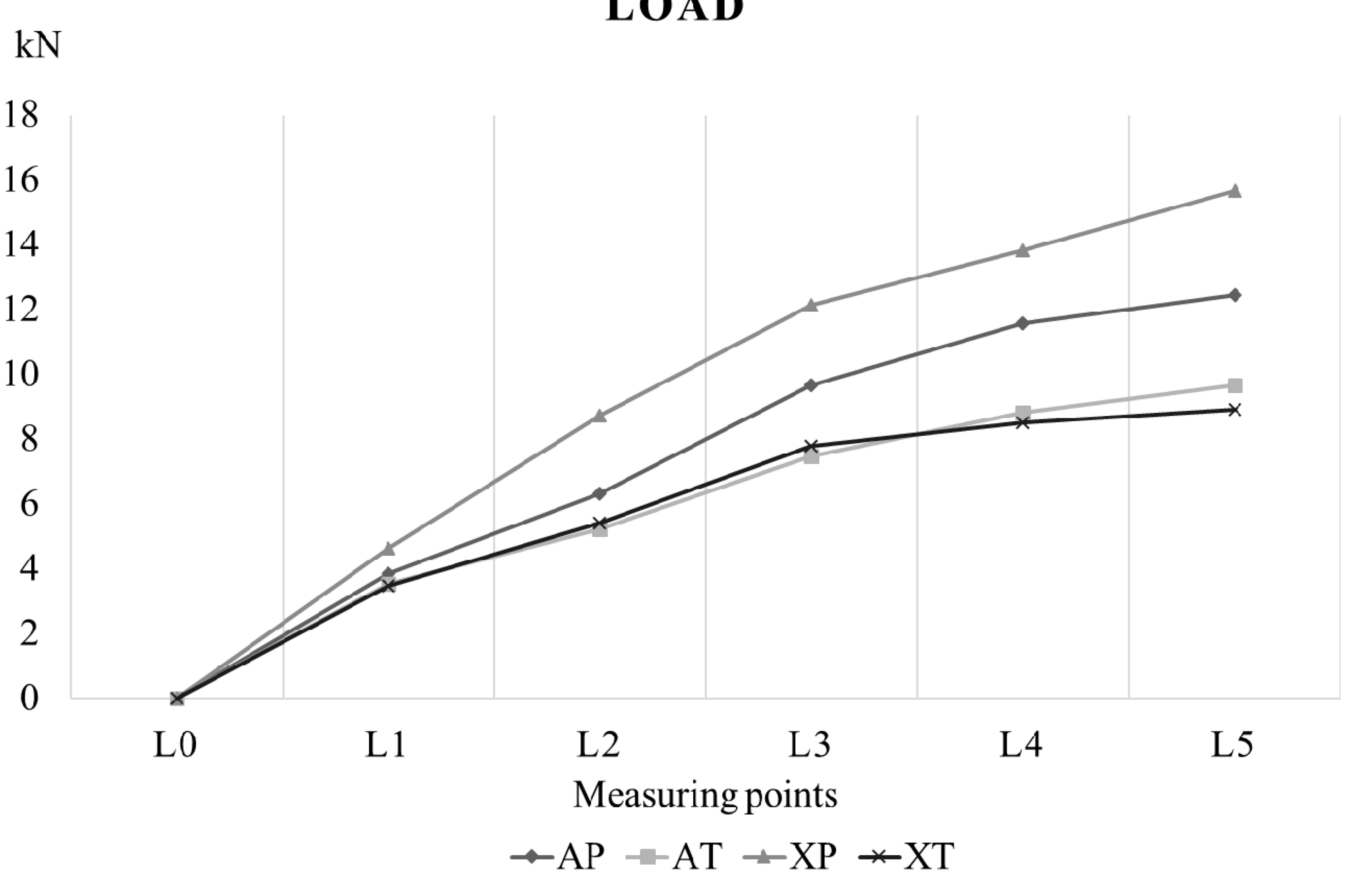

Figure 3. Load trend at the various measuring points. Each point represents the average of the nine replications. The acronyms represent: Axis rope system and Prusik (AP); Axis rope system and Valdotain tresse (AT); XTC rope system and Prusik (XP); XTC rope system and Valdotain tresse (XT). On the $x$-axis: L0 -initial state; L1 $-50 \mathrm{~mm}$ progress; L2-100 $\mathrm{mm}$ progress; L3-150 $\mathrm{mm}$ progress; L4-200 mm progress; L5-250 $\mathrm{mm}$ progress. 
Following the trend at all points of $\mathrm{AP}$ and $\mathrm{XP}$, it can be observed that the difference is consistently evident, both with respect to treatment of the ropes with the Valdotain tresse (on average: AP-AT 19\%, AP-XT 19.7\%, XP-AT 51.7\% and XP-XT 39.4\%) and between them, with a mean of $22.4 \%$. The Prusik knot exerted a greater grip on the rope, thus leading the machine, in its short stroke, to apply a greater load than the tresse. Comparing the maximum load, the AT and XT treatments $(9.3 \mathrm{kN}$ and $8.6 \mathrm{kN})$ were similar, in contrast to AP and XP (11.9 kN and $15.1 \mathrm{kN})$, which differed by approximately $4 \mathrm{kN}$ (Figure 3). As with the load, the sliding of the friction nodes showed no differences up to the L2 measurement point (Figure 4). The effect was more pronounced at L3, where the AP treatment showed differences compared to the other three treatments (AT 62.8\%, XT 66.2\%, XP 62.2\%). The advancement of the test showed increasing creep; the treatments that suffered the greatest effect were XT and AT, with values of 8.97 and $7.17 \mathrm{~cm}$, respectively, with a percentage variation of $25.1 \%$. The AP treatment was found to have reduced creep by about $50 \%$ compared to the others, with a maximum value of $4.73 \mathrm{~cm}$. The reduction in diameter, in contrast to the other parameters evaluated, showed effects from the lowest loads (Figure 5). The AT treatment showed the smallest diameter reduction compared to the other treatments, with an average in L 5 of $-1.72 \mathrm{~mm}$ - while the maximum effect was observed in the XP treatment, with an average in $\mathrm{L} 5$ of $-3 \mathrm{~mm}$, with a percentage variation of $42.7 \%$.

\section{FRICTION HITCH SLIP}

$\mathrm{cm}$

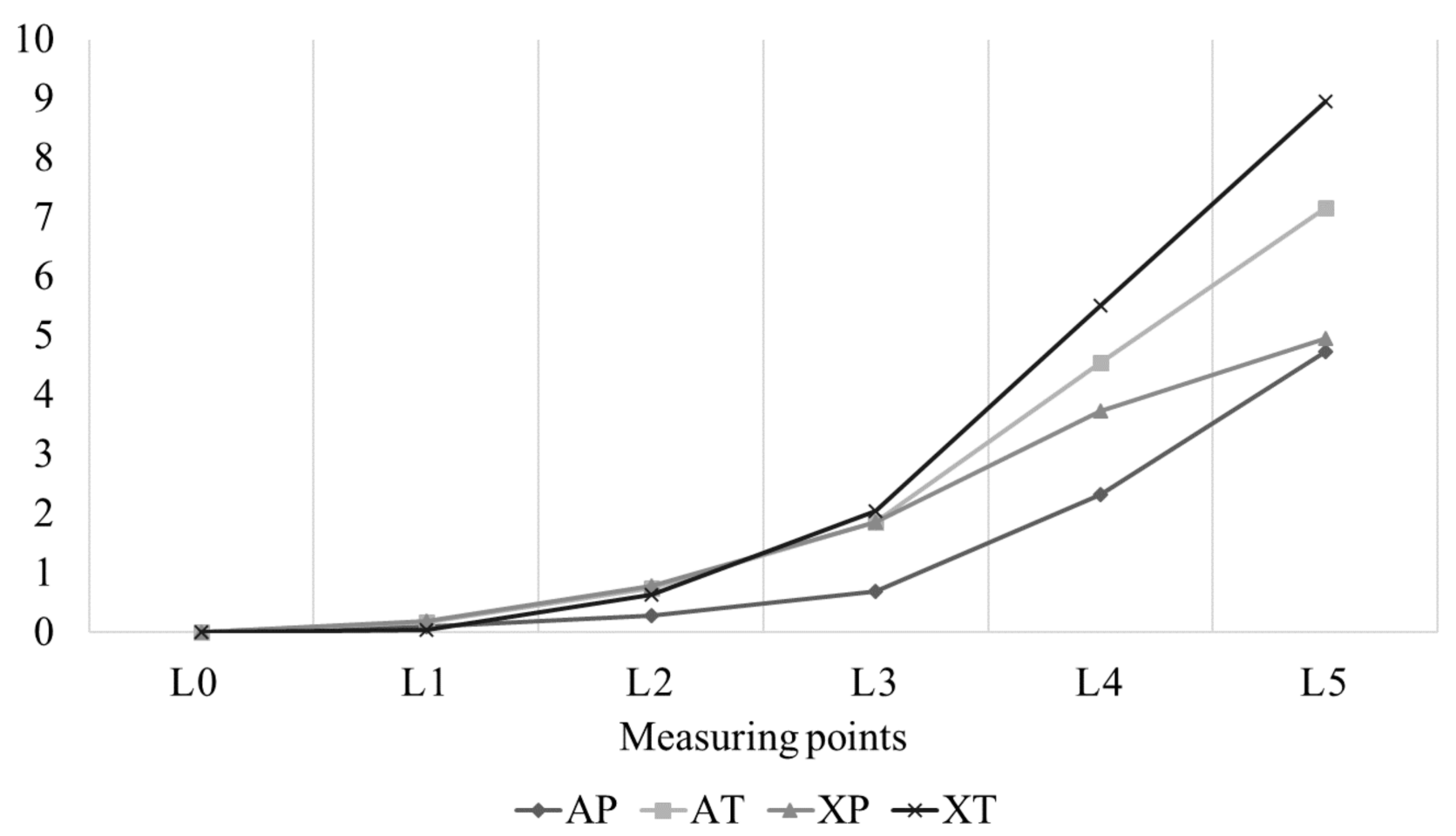

Figure 4. Friction hitch slip at the various measuring points. Each point represents the average of the nine replications. The acronyms represent: Axis rope system and Prusik (AP); Axis rope system and Valdotain tresse (AT); XTC rope system and Prusik (XP); XTC rope system and Valdotain tresse (XT). On the $x$-axis: L0_-initial state; L1-50 mm progress; L2-100 mm progress; L3-150 mm progress; L4-200 mm progress; L5-250 mm progress. 


\section{DIAMETER REDUCTION}

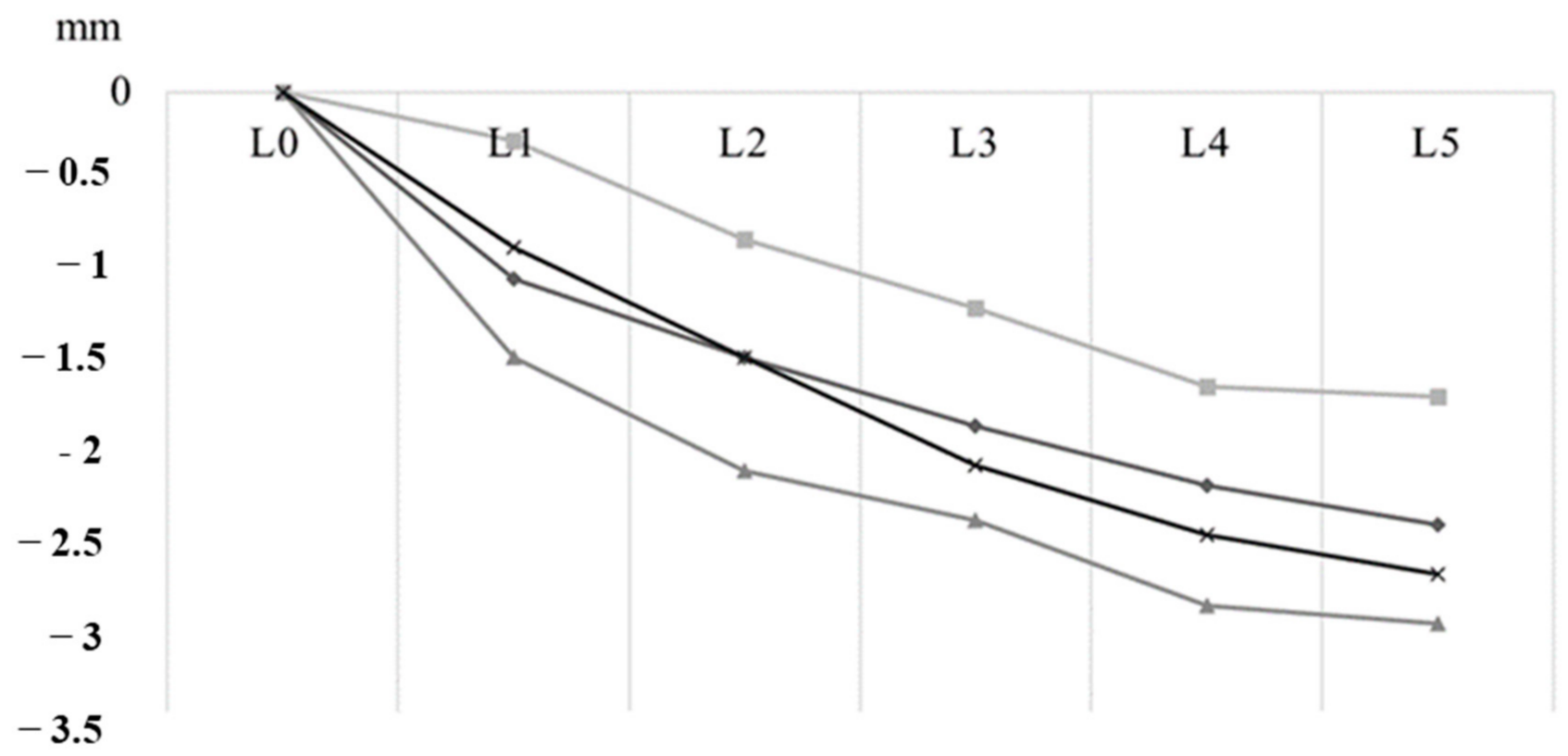

\section{Measuring points \\ $\rightarrow \mathrm{AP} \rightarrow \mathrm{AT} \rightarrow \mathrm{XP} * \mathrm{XT}$}

Figure 5. Rope diameter variation at the various measuring points. Each point represents the average of the nine replications. The acronyms represent: Axis rope system and Prusik (AP); Axis rope system and Valdotain tresse (AT); XTC rope system and Prusik (XP); XTC rope system and Valdotain tresse (XT). On the $x$-axis: L0—initial state; L1—50 mm progress; L2-100 mm progress; L3-150 mm progress; L4-200 mm progress; L5-250 $\mathrm{mm}$ progress.

The application of the MANOVA test showed significant differences among the effects on treatments by knot type, rope type, and the interaction between these. Tukey's test showed that a significant effect on the load was caused by the knot, for both Valdotain and Prusik knots, at $\alpha=0.05$ ( $p$ value $<0.001$ ). The same situation was observed for the variable $S$ ( $p$ value $<0.001$ ). For the diameter, a significant effect was caused by the type of rope for both Axis and XTC at $\alpha=0.05$ ( $p$ value $<0.001$; Table 3). Given these effects, a greater knot friction corresponded to an increase in load and less slippage along the rope, and conversely, less knot friction corresponded to less load and more slippage- this effect was mainly due to the type of knot. On the other hand, the variation in the diameter of the rope was mainly determined by the type of rope; the $11 \mathrm{~mm}$ rope proved to be less deformable than the $12.7 \mathrm{~mm}$ rope, regardless of the knot that was used.

Table 3. Test HSD Tukey significant effects of hitches and ropes on variables. The load to which the rope/node system has been subjected $(\mathrm{C}, \mathrm{kN})$; sliding of the clutch knot along the rope $(\mathrm{S}, \mathrm{cm})$; variation of the diameter of the rope $(\Delta \mathrm{f}, \mathrm{mm})$.

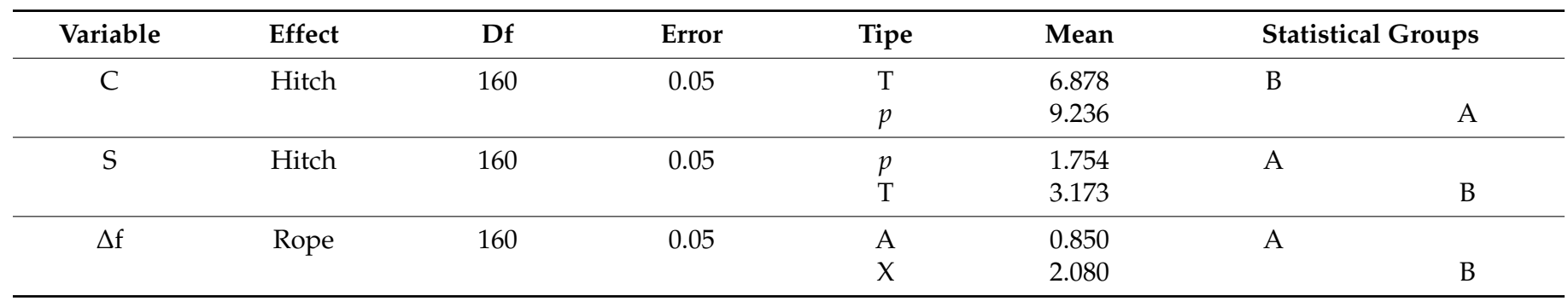


Regression analysis was applied to observe the interactions between variables. Table 4 shows the significant results of the analysis, which revealed a relationship between the dependent variables C (load) and DF (diameter reduction), as well as S (friction hitch slip). Furthermore, DF was considered as a dependent variable, showing a significant relationship with the variable $\mathrm{S}$. Table 4 shows, although not markedly, a relationship between load and diameter variation $\left(R^{2}\right.$ adj. 0.445$)$, between load and knot slippage $\left(R^{2}\right.$ adj. 0.418$)$ and between slippage and diameter variation (0.378; Table 4). However, the multiple regression model better described the interactions of the variables with each other $\left(R^{2}\right.$ adj. $\left.=0.535\right)$ - showing a final combined effect rather than the effectiveness of any single variable (Table 5).

Table 4. Regression analysis for the dependent variable C (load) as a function of $\Delta \mathrm{f}$ (diameter reduction) and $\mathrm{S}$ (friction hitch slip) for the first two sections, and in the last section for the dependent variable $\Delta \mathrm{f}$ as a function of $\mathrm{S}$. Regressions that showed statistical significance were reported.

\begin{tabular}{|c|c|c|c|c|}
\hline & B & Err. Std. di B & $t(162)$ & $p$-Level \\
\hline Intercept & 4.404 & 0.371 & 11.885 & $<0.001$ \\
\hline$\Delta \mathrm{f}$ & 2.518 & 0.219 & 11.477 & $<0.001$ \\
\hline \multicolumn{5}{|c|}{ Dependent variable: $C ; \mathrm{R}^{2}$ adj. $=0.445 ; \mathrm{F}(1.162)=131.730 ; p<0.000 ;$ Err.Standard: 2.636} \\
\hline Intercept & 5.403 & 0.314 & 17.216 & $<0.001$ \\
\hline$S^{1}$ & 2.007 & 0.207 & 9.680 & $<0.001$ \\
\hline$S^{2}$ & -0.147 & 0.019 & -7.654 & $<0.001$ \\
\hline \multicolumn{5}{|c|}{ Dependent variable: $C ; \mathrm{R}^{2}{ }_{\text {adj }} .=0.418 ; \mathrm{F}(2.161)=59.595 ; p<0.000 ;$ Err.Standard: 2.699} \\
\hline Intercept & 0.772 & 0.086 & 8.950 & $<0.001$ \\
\hline$S$ & 0.460 & 0.057 & 8.075 & $<0.001$ \\
\hline$S^{2}$ & -0.031 & 0.005 & -5.831 & $<0.001$ \\
\hline
\end{tabular}

Table 5. Multiple regression analysis for the dependent variable C (load) as a function of the friction hitch slip and diameter reduction $(\mathrm{S}, \Delta \mathrm{f})$. Regressions that showed statistical significance were reported.

\begin{tabular}{ccccc}
\hline & B & Err. Std. di B & t (160) & $p$-Level \\
\hline Intercept & 4.129 & 0.343 & 12.026 & $<0.001$ \\
$S$ & 1.248 & 0.220 & 5.678 & $<0.001$ \\
$\Delta \mathrm{f}$ & 1.651 & 0.256 & 6.441 & $<0.001$ \\
$\mathrm{~S}^{2}$ & -0.096 & 0.019 & -5.091 & $<0.001$ \\
\hline
\end{tabular}

Dependent variable: $C ; R^{2}{ }_{\text {adj }}=0.535, F(3.160)=63.548 p<0.000$ Err. Standard: 2.412

The analysis of the results revealed some expected differences that had already appeared during the tests. The most evident differences emerged according to the type of knot used, both in terms of load application and knot slip. Thus, the type of knot, not the type of rope, would appear to be determinant-an interesting factor also found by other authors [27]. These authors also examined the slippage of friction hitches; they looked for the first sign of failure in the friction system and observed that the first sign of failure in Prusik knots occurred between about 4 and $6 \mathrm{kN}$-an observation partially replicated in this work, with a minimum of $4 \mathrm{kN}$ in the case of the $11 \mathrm{~mm}$ rope, to a maximum of $10 \mathrm{kN}$ for the $13 \mathrm{~mm}$ rope [27]. The treatments with the Prusik knot achieved higher loads and a lower slip, while in the cases in which the Valdotain tresse was applied, the slip of the knot was higher in the case of lower loads. Similarly, the Prusik knot caused a greater reduction in the diameter of the rope than the tresse. These effects could be caused by the greater friction with the Prusik knot compared to the tresse. The effect of the rope type can be observed in the reduction of the rope diameter, since XTC underwent substantial variations compared to AXIS. This could be due to the material, the braiding of the strands, 
and the rope diameter. As also observed by Evans [20] in Prusik breaking tests, this knot is influenced by the diameter of the rope to which it is anchored. In this regard, for larger diameter materials, in addition to a greater reduction in diameter than for smaller diameter materials, there is also a tendency to retain less of their original strength than unknotted rope, as found by Evans (2016), Detter et al. (2008) and Vines and Hudson (2004) [24,28,29]. Another aspect to be considered, according to Evans [24], is the type of material; according to Evans, polyamide seems to be stronger than polyester-consequently, the composition of the rope and the lanyard of the friction knot affects resistance. Such considerations have also been made by Borwick, as well as the loss of breaking strength due to the presence of knots [30-32]. A climber must also consider deterioration due to environmental factors such as water, UV rays, freezing, heat and particles embedded between the rope fibers [31]. It must also be borne in mind that all knots break at between 55 and $84 \%$ of the rope's maximum strength [33].

Over the years, engineering has provided new materials and new geometries for strand braiding, so it is important to investigate the relationships between the knot/rope, sheath, rope core system between material type, braiding, grip, knot type or mechanical descender and wear, as also reported by Evans [20]. However, more data are needed to apply the results on a larger scale, given the great variability between techniques, equipment and knots [34]. Furthermore, it is not trivial to understand the dynamics of synthetic ropes, since a description of their load-strain properties should be further considered. However, these properties are quite complex to evaluate, since synthetic ropes exhibit hysteresis under cyclic loading as it is nonlinear and time dependent $[33,35,36]$. This data can be useful in determining whether information about how knots function among the climbers is valid, and thus establishing whether they are acting on incorrect assumptions-even taking into account that only when climbing the shaft is the load 1.3 times the operator's weight $[37,38]$. However, it should be pointed out that these data are not applicable for use as insurance in a dynamic event, as is pointed out in other studies [20]. Therefore, it is desirable that experimentation continues, with dynamic tests for testing the reaction of the knots to a falling body, and tests under cyclic loading for evaluation of system hysteresis, since ropes in arboricultural operations are subjected to repeated stresses-leading to an increase in stiffness [35]. In fact, as has been observed by other authors, in each successive fall the impact force measured was greater. This shows that the rope needs some time to recover its properties [39]. In addition to empirical and small-scale studies, we need studies with larger samples in order to observe variability between systems and equipment [40-42]. Furthermore, as some authors have stated, it would be useful to have uniform safety standards for arborists in different countries [7].

\section{Conclusions}

This study is a preliminary work which should be repeated for other types of knots and ropes, but has included many laboratory tests that are reproducible, given the large number of replications and the results obtained. The data from these tests showed a high tightness for the two knots tested, and the possibility of using both knots with both ropes. The Prusik knot showed higher friction and greater grip than the Valdotain tresse, and the XTC rope showed greater deformability in diameter than the Axis rope.

This information can help arborists to choose equipment and techniques according to their needs, and at the same time, begin to address technical regulations. The further development of this research, repeated for other types of knots and ropes, would provide valuable information applicable in the fields of technical design, operations, and legislation.

Author Contributions: Conceptualization, L.B., M.C., A.C.; Data analysis, L.B., R.P.; Methodology, L.B., M.C., R.P., M.S.; Writing—original draft, L.B., R.P., V.D.S.; Review and editing, R.P., V.D.S., M.C., A.C. All authors have read and agreed to the published version of the manuscript.

Funding: This research received no external funding. 
Acknowledgments: The authors are grateful to the professional arborists of the following companies: Ecologistica Srl and UTM Soc. Coop.

Conflicts of Interest: The authors declare no conflict of interest.

\section{References}

1. Warguła, Ł.; Kukla, M.; Lijewski, P.; Dobrzynski, M.; Markiewicz, F. Influence of Innovative Woodchipper Speed Control Systems on Exhaust Gas Emissions and Fuel Consumption in Urban Areas. Energies 2020, 13, 3330. [CrossRef]

2. Xu, C.; Dong, L.; Yu, C.; Zhang, Y.; Cheng, B. Can forest city construction affect urban air quality? The evidence from the Beijing-Tianjin-Hebei urban agglomeration of China. J. Clean. Prod. 2020, 264, 121607. [CrossRef]

3. Warguła, Ł.; Kukla, M.; Wieczorek, B.; Krawiec, P. Energy consumption of the wood size reduction processes with employment of a low-power machines with various cutting mechanisms. Renew. Energy 2022, 181, 630-639. [CrossRef]

4. Wargula, L.; Kukla, M.; Krawiec, P.; Wieczorek, B. Impact of number of operators and distance to branch piles on woodchipper operation. Forests 2020, 11, 598. [CrossRef]

5. Kane, B. Frictional properties of arborist rigging blocks. Urban For. Urban Green. 2019, 42, 31-38. [CrossRef]

6. Kane, B. Forces generated in rigging trees with single and co-dominant stems. Urban For. Urban Green. 2017, 24, 14-18. [CrossRef]

7. Lim, J.; Kane, B.; Bloniarz, D. Arboriculture safety standards: Consistent trends. Urban For. Urban Green. 2020, 53, 126736. [CrossRef]

8. Proto, A.R.; Mazzocchi, F.; Cossio, F.; Bortolini, L.; Pascuzzi, S.; Caruso, L.; Diano, M.; Zimbalatti, G. A Survey on Occupational Injuries in Works on Trees in Italy. Procedia-Soc. Behav. Sci. 2016, 223, 435-441. [CrossRef]

9. Anderson, D.L.; Koomjian, W.; French, B.; Altenhoff, S.R.; Luce, J. Review of rope-based access methods for the forest canopy: Safe and unsafe practices in published information sources and a summary of current methods. Methods Ecol. Evol. 2015, 6, 865-872. [CrossRef]

10. Kane, B. Compatibility of toothed ascenders with arborist climbing ropes. Arboric. Urban For. 2011, 37, $180-185$.

11. Mazzocchi, F.; Cecchini, M.; Monarca, D.; Colantoni, A.; Caruso, L.; Colopardi, F.; Giuliano, C.; Rapiti, R. An Overview of Risk Assessment for Tree Climber Arborists. Contemp. Eng. Sci. 2015, 8, 1171-1177. [CrossRef]

12. EN 12841:2007. Available online: http://store.uni.com/catalogo/index.php/catalog/product/view/id/67266/s/uni-en-128412007/category /68/?__store=en\&josso_back_to=http\%3A\%2F\%2Fstore.uni.com\%2Fjosso-security-check.php\&josso_cmd= login_optional\&josso_partnerapp_host=store.uni.com\&__from_sto (accessed on 24 March 2021).

13. EN 341:2011. Available online: http:/ / store.uni.com/catalogo/en-341-2011 (accessed on 24 March 2021).

14. Adams, M. An Overview of Climbing Hitches. Tree Care Ind. 2004, 13, 29-35.

15. Kane, B. Breaking load of hitches and ropes used in rigging. Arboric. Urban For. 2012, 38, 1-5.

16. Simon, J. Physical knots. Contemp. Math. 2002, 304, 1-30. [CrossRef]

17. Bianchini, L.; Cecchini, M.; Gallo, P.; Biocca, M. A Survey on Rope-Based Ascending Techniques and Materials of Professional Arborists in Italy. Environ. Sci. Proc. 2020, 3, 23. [CrossRef]

18. Bavaresco, P. Ropes and Friction Hitches used in Tree Climbing Operations. Treevolution 2007, 1-87. Available online: http: / / www.paci.com.au/downloads_public/knots/14_Report_hitches_PBavaresco.pdf (accessed on 24 March 2021).

19. Evans, T. A Review of Friction Hitch Testing. Int. Tech. Rescue Symp. 2017, 1-18. Available online: https://www.elementrescue. com/A-Review-of-Friction-Hitch-Research-Slides_Evans[1].pdf (accessed on 24 March 2021).

20. Evans, T. Empirical Breaking Strengths of Single Prusiks in Four Diameters on $11 \mathrm{~mm}$ Static Rope. 2012. Available online: https:// docplayer.net/37631648-Empirical-breaking-strengths-of-single-prusiks-in-four-diameters-on-11-mm-static-rope.html (accessed on 24 March 2021).

21. Rocca, M.; Brenta, P. Manuale di Arrampicata e Lavoro su Alberi; Regione Piemonte: Torino, Italy, 2010.

22. Kane, B. Loads borne by a tie-in point (TIP) during arboricultural climbing operations. Urban For. Urban Green. 2020, 49 , 126625. [CrossRef]

23. Kane, B.; Arwade, S.R. Quantifying tension and deflection in pre-tensioned speedlines carrying a load. Urban For. Urban Green. 2020, 48, 126514. [CrossRef]

24. Evans, T. A Review of Knot Strength Testing. In Proceedings of the International Technical Rescue Symposium; 2016. Available online: http:/ / www.paci.com.au/downloads_public/knots/Knot-Testing_Thomas-Evans_2016.pdf (accessed on 24 March 2021).

25. EN 1891:2001. Available online: http://store.uni.com/catalogo/uni-en-1891-2001?__store=en\&_from_store=it (accessed on 24 March 2021).

26. EN 566:2006. Available online: http:/ / store.uni.com/catalogo/en-566-2006 (accessed on 24 March 2021).

27. Michalička, V.; Telvak, R. Friction knots-Their strength under static load. J. Outdoor Act. 2021, 14, 7-16. [CrossRef]

28. Detter, A.; Cowell, C.; McKeown, L.; Howard, P. Evaluation of Current Rigging and Dismantling Practices Used in Arboriculture; The Health and Safety Executive: Norwich, UK, 2008.

29. Vines, T.; Hudson, S. High Angle Rescue Techniques, 3rd ed.; Jones \& Bartlett Learning: London, UK, $2004 ;$ ISBN 0323019145.

30. Borwick, G.R. Mountaineering ropes. Alp. J. 1973, 1, 67-70.

31. Šimon, J.; Dekýš, V.; Palcek, P. Revision of commonly used loop knots efficiencies. Acta Phys. Pol. A 2020, 138, 404-420. [CrossRef]

32. Cecchini, M.; Piccioni, F.; Ferri, S.; Coltrinari, G.; Bianchini, L.; Colantoni, A. Preliminary Investigation on Systems for the Preventive Diagnosis of Faults on Agricultural Operating Machines. Sensors 2021, 21, 1547. [CrossRef] 
33. Mclaren, A.J. Design and Performance of Ropes for Climbing and Sailing. Proc. Inst. Mech. Eng. Part L J. Mater. Des. Appl. 2006, 220,1-12. [CrossRef]

34. Kane, B. Loads borne by a tie-in point during ascents and descents on a basal-anchored stationary rope system. Urban For. Urban Green. 2020, 51, 126687. [CrossRef]

35. Huang, W.; Liu, H.; Hu, C. Modeling the stress-strain properties of synthetic fiber mooring lines under cyclic loading. In Proceedings of the Twenty-Fourth International Ocean and Polar Engineering Conference, Busan, Korea, 15-20 June 2014; pp. 126-133.

36. Sry, V.; Mizutani, Y.; Endo, G.; Suzuki, Y.; Todoroki, A. Consecutive Impact Loading and Preloading Effect on Stiffness of Woven Synthetic-Fiber Rope. J. Text. Sci. Technol. 2017, 3, 1-16. [CrossRef]

37. Kane, B. Forces and motion associated with arboricultural climbing. Urban For. Urban Green. 2021, 57, 126944. [CrossRef]

38. Marucci, A.; Monarca, D.; Cecchini, M.; Colantoni, A.; Di Giacinto, S.; Cappuccini, A. The heat stress for workers employed in a dairy farm. J. Agric. Eng. 2013, 44, 170-174. [CrossRef]

39. Szust, A.; Banas, Z.; Zak, A. Experimental evaluation of climbing ropes under dynamic load. Mater. Today Proc. 2017, 4, 5963-5968. [CrossRef]

40. Evans, T. Science as Applied to Technical Rescue Research. In Proceedings of the International Technical Rescue Symposium; 2010. Available online: https:/ / drive.google.com/file/d/1tlcc00s0bC9TxgJ0BRyqk83T2kssFeUZ/view (accessed on 24 March 2021).

41. Evans, T.; Stavens, A. Basic Research Methods for Technical Rescue Science. In Proceedings of the International Technical Rescue Symposium; 2012; p. 7. Available online: https://drive.google.com/file/d/1NqbJg7g8HSW4_wZBJwbdAQIvXUvJ21c9/view (accessed on 24 March 2021).

42. Marucci, A.; Pagniello, B.; Monarca, D.; Cecchini, M.; Colantoni, A.; Biondi, P. Heat stress suffered by workers employed in vegetable grafting in greenhouses. J. Food Agric. Environ. 2012, 10, 1117-1121. 